\title{
IMPACT OF CHANGING WATER LEVEL ON SHREW POPULATIONS IN THE KIS-BALATON WETLANDS, WESTERN HUNGARY
}

\author{
CZABÁN, D. ${ }^{1}{ }^{*}$-ZSEBÖK, S. $^{2}$ - CSERKÉSZ, T. ${ }^{1}$ - FARKAS, J. ${ }^{1}$ \\ ${ }^{1}$ Eötvös Loránd University, Department of Systematic Zoology and Ecology \\ Pázmány Péter sétány 1/C, H-1117 Budapest, Hungary \\ (phone: +36-1-381-2193; fax: +36-1-381-2194) \\ ${ }^{2}$ Sensory Ecology Group, Max Planck Institute for Ornithology, Eberhard-Gwinner Str. \\ MTA-ELTE-MTM Ecology Research Group, H-1083 Budapest, Ludovika tér 2, Hungary \\ (phone: +36-1-210-1075/5037) \\ *Corresponding author \\ e-mail: david.czaban@gmail.com \\ (Received $9^{\text {th }}$ Jul 2012; accepted $2^{\text {nd }}$ Aug 2014)
}

\begin{abstract}
We studied the impact of water level changes on the dynamic of small mammal communities in the Kis-Balaton wetland area of Hungary between 2005-2008. Reconstruction in wetland areas is often associated with flooding of the wetlands. These processes cause enormous changes for small mammals living there. During this period the maximum water level change was $60 \mathrm{~cm}$. At high water the study area was totally flooded; whereas dry areas occur during lower water levels. We noted that Neomys fodiens and Arvicola amphibius live only in areas with deep water; whereas Sorex species and other small rodents require dry areas while Neomys anomalus lives in both types of areas. Only subadult shrews appeared in the recolonized territories. These results suggest that after flooding, the species composition and the abundance of species in the community change quickly and profoundly.
\end{abstract}

Keywords: flooding; rodents; shrews; community structure; wetland reconstruction

\section{Introduction}

Riparian areas have more small mammal species (shrews, mice, voles) than adjacent uplands (Doyle, 1990). These areas provide superior habitat for small animals because of greater availability of water, plant forage, and invertebrates (Doyle, 1990). The more dense herbaceous vegetation of the floodplain may also provide better protection from predation (Blem and Blem, 1975), therefore small mammals prefer grassy riparian areas to deciduous floodplain forests or upland forests (Geier and Best, 1980).

Floods greatly affect the small mammal populations (Jacob, 2002). The species show different responses to inundation but they tend to remain in the original home range until ,forced” to leave (Andersen et al., 2000). Terrestrial species are capable of using arboreal refugees (Ellis et al., 1997, Andersen et al., 2000). Although bottomland flooding do not inhibit their movements, mice utilize peripherical portions of flooded areas more (Ruffer, 1961). After flooding event the recolonisation is a slow process, resulting in a heterogeneous distribution of small mammals in the floodplains (Wijnhoven et al., 2006). Most floodplain residents disappear over the flood period and they do not come back (Andersen et al., 2000).

Depending on the author quoted and the area of study, the result of density studies of shrew populations is highly variable. Lardet (1988) found that a Neomys fodiens (Pennant, 1771) specimen occupies $207 \pm 93 \mathrm{~m}^{2}$ in summer and $106 \pm 45 \mathrm{~m}^{2}$ in winter. 
According to Van Bemmel and Voesnek (1984) an individual lives within $190 \mathrm{~m}^{2}$. Sorex araneus (Linnaeus, 1758) uses $373 \mathrm{~m}^{2}$ (Crowcroft, 1957) but Khylap (1980) suggested much larger home ranges of this species (S. araneus: $1600-2300 \mathrm{~m}^{2}$ ). When Rychlik et al. (2004) tracked shrews in a large outdoor enclosure $2500 \mathrm{~m}^{2}$, home ranges averaged $429 \mathrm{~m}^{2}$ in $N$. fodiens, $303 \mathrm{~m}^{2}$ in Neomys anomalus (Cabrera, 1907), and 790 $\mathrm{m}^{2}$ in S. araneus, whereas $2626 \mathrm{~m}^{2}$ in $N$. fodiens and $2190 \mathrm{~m}^{2}$ in $S$. araneus when they were tracked as free ranging in a river valley. However, free ranging shrews were tracked under much drier conditions than enclosure shrews (Rychlik et al., 2004). Thus, population density is highly variable and depends on the species, habitat quality, climate as well as the presence of other species (Mohammadi, 2010).

Most shrews are essentially annuals (Churchfield, 1990). In central and eastern Europe Soricinae shrews are only capable of reproduction in the second year of their life (Gliwicz and Jancewicz, 2001). Only 50\% of shrews survive the first two months of life but over $80 \%$ of survivers overwinter. Twenty to thirty percent of shrews survive to breed (Churchfield, 1980). During and after the summer breeding season, population density is highest, and so is the rate of dispersal (Churchfield, 1984). During this time shrews can be found in many different habitats, even those that are less suitable (Dehnel, 1950). In winter the population density decreases, but the populations are more stable and shrews are more likely to inhabit optimal sites (Churchfield et al., 2000). The small mammals use some microhabitats more frequently than others, suggesting that they perceive the differences in habitat quality (Simonetti, 1989).

In this study, we investigated: (1) the species richness of wetlands with different water cover; (2) the microhabitat selection and (3) the impact of water level changes in small mammals.

\section{Materials and methods}

This study was carried out in the Kis-Balaton wetland area $\left(147,5 \mathrm{~km}^{2}\right.$, Natural Park, Ramsar site, Natura 2000 site, IBA) of Hungary. Two lakes belong to this area, each surrounded by dikes. Herbaceous wet marshes can be found outside the dams of the second basin where three study plots were appointed in three different localities according to gradient of wetness along the dam. Plot 1-2 and 2-3 were 3.2 and $3.8 \mathrm{~km}$ from each other, respectively. Therefore the animals could not moved between the plots. Each plot was covered with 49 plastic box live-traps (Polish type) in a grid of $10 \mathrm{~m} \mathrm{x} 10$ $\mathrm{m}$ (7 rows of 7 traps each). The first row of each plot was laid $10 \mathrm{~m}$ from a canal and paralell to it. Between 2005 and 2008, 11 4-nights trapping sessions were performed in two months from March until November. Traps were baited with minced meat. Traps were opened shortly before sundown, and were checked every 4 hours and closed around sunrise. Animals were marked individually by toe tattooing. The age (subadultadult) and gender (male-female) of shrews was also noted. Shrews are considered subadults in the first year of their life and adults when their gonads become visible.

During the study period the maximum water level change was $60 \mathrm{~cm}$ in the plot 1 . (Fig. 1). The area of water cover varied between $2 \%$ and $100 \%$. Four types of microhabitats were distinguished in the area characterised by their dominant plant species as Bidens tripartitus, Glyceria maxima, Phragmites australis, and Carex acutiformis, respectively. A willow bush (Salix sp.) grew in the plot, and the bank of a small pond also bordered on the plot 1 (Fig. 1). Plot 2 was homogenously covered by Solidago sp. There were no trappings in this plot between June and October of 2007. 
This area was never covered by water. Plot 3 was covered by a young alder forest (Alnus glutinosa), where the trees were 2-3 m tall. Two types of microhabitats were noted each distinguished by the characteristic herbaceous plants: Carex acutiformis $-C$. riparia mixed with Solidago sp., and Phragmites australis. The water cover was always less than $1 \%$.

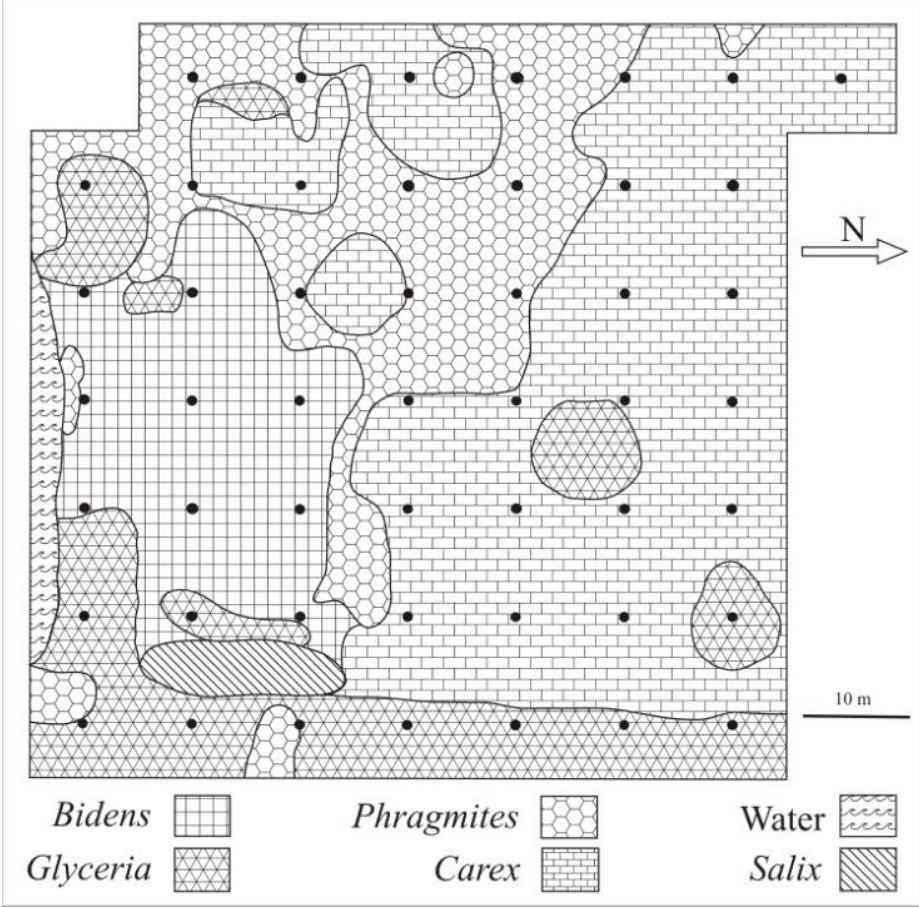

Figure 1. Microhabitat map of Plot 1. The black dots mark the location of traps. The upper (western) row of traps was slipped because of deep water.

The water level varied seriously only in the plot 1 where the 11 trapping periods were grouped according to the water levels. Eighty percent or more of the trapping locations were dry at low water level (4 periods). Water covered 50-60\% of the area during medium water level (4 periods). The area was totally flooded during high water level ( 3 periods). The 4 periods of medium water level were separated into two groups (2005-2006 and 2007-2008) because of a change in vegetation type between 2005-2006 and 2007-2008.

The patch preference value of small mammals was calculated using Ivlev's index and its significance was checked by Bonferroni's z-test. Statistica 8.0 (StatSoft Inc.) was used for analysing the impact of water-level changes using variance component analysis (VCA). Values of Shannon-Wiener diversity and evenness were calculated for each trapping period. Bonferroni's z-test and seasonal differences in community diversity were analysed by the inter-diversity t-test and by diversity ordering, using the $\mathrm{NuCoSa}$ 1.5 and DivOrd 1.9 programs (Tóthmérész, 1996, 1997).

\section{Results}

Eleven small mammal species were recorded in the plots during the entire sampling period: 5 species of shrews: Miller's water shrew (Neomys anomalus), eurasian water 
shrew (Neomys fodiens), common shrew (Sorex araneus), pygmy shrew (Sorex minutus Linnaeus, 1766), bicolored white-toothed shrew (Crocidura leucodon Hermann, 1780) and 6 species of rodents: striped field mouse (Apodemus agrarius Pallas, 1771), yellownecked mouse (Apodemus flavicollis Melchior, 1834), harvest mouse (Micromys minutus Pallas, 1771), european water vole (Arvicola amphibius Linnaeus, 1758), field vole (Microtus agrestis Linnaeus, 1761), and bank vole (Myodes glareolus Schreber, 1780). The Shannon-Wiener index did not support significant differences in species versus season.

For the five shrew species captured in the studied plots during the entire sampling program (Table 1) the numbers of recaptured individuals were small, less than $10 \%: 8$ of 97 in $N$. anomalus, 0 of 12 in $N$. fodiens, 19 of 266 in $S$. araneus, 2 of 30 in $S$. minutus, and 0 of 7 in C. leucodon. In order to estimate population size more recaptures would be required; therefore, the population sizes were not calculated.

Table 1. Number of trapped shrews in the plots 1, 2, and 3 set in the Kis-Balaton area of Hungary.

\begin{tabular}{l|c|c|c|c|c}
\hline & N. anomalus & N. fodiens & S. araneus & S. minutus & C. leucodon \\
\hline Plot 1 & 65 & 9 & 85 & 4 & 0 \\
Plot 2 & 5 & 0 & 59 & 3 & 6 \\
Plot 3 & 27 & 3 & 122 & 23 & 1 \\
Total & 97 & 12 & 266 & 30 & 7 \\
\hline
\end{tabular}

Only in Sorex araneus the number of captures was high enough to calculate periods of peak density of adults as well as proportion of sexes. The proportion of adult shrews was highest between May and June (see Table 2 and Fig. 2). The proportion of females to males varied but there were always more females than males of $S$. araneus (female:male ratio was 3:1 in plot 1, 1:1 in plot 2, and 9:1 in plot 3).

Table 2. The proportion of Sorex araneus adults (\%) in the sampling periods by month and year in the plots 1, 2, and 3. No trappings were performed in the sampling periods marked with black background.

\begin{tabular}{|c|c|c|c|c|c|c|c|c|c|c|c|}
\hline & 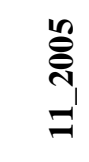 & 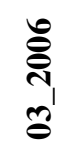 & 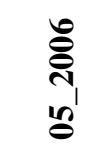 & 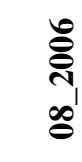 & 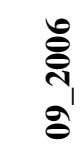 & 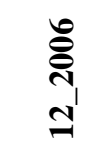 & 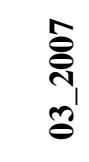 & 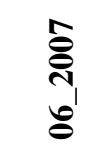 & $\begin{array}{l}\hat{\stackrel{\hat{~}}{1}} \\
\infty^{\prime}\end{array}$ & 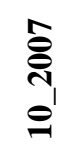 & $\begin{array}{l}\infty \\
\stackrel{\tilde{N}}{1} \\
\overbrace{1}^{\prime}\end{array}$ \\
\hline Plot 1 & 0 & 0 & 25 & 6.25 & 0 & 0 & 0 & 0 & 0 & 0 & 0 \\
\hline Plot 2 & 14.3 & 0 & 25 & 15.8 & 15.4 & 0 & 33.3 & & & & 0 \\
\hline Plot 3 & 23.8 & 0 & 18.8 & 0 & 0 & 8.33 & 7.14 & 11.8 & 0 & 0 & \\
\hline
\end{tabular}

Four microhabitats, depending on floral type were established in the plot 1. At all water levels, Neomys anomalus and Sorex araneus preferred only a dense foliage of Carex acutiformis microhabitat type (Figs. 3 and 5). N. fodiens showed variable microhabitat preference: at high water level it lived in the patch with Glyceria maxima, wheras at medium water levels it preferred the open microhabitat of Bidens tripartitus type (Fig. 4). 
Plot 1

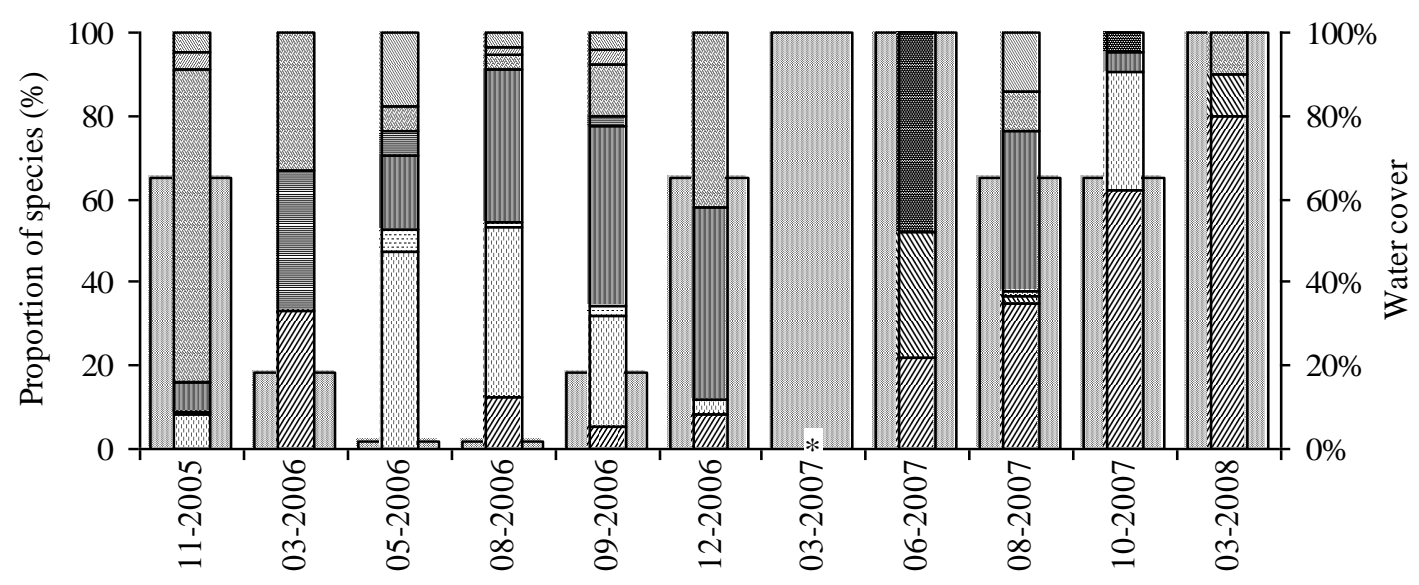

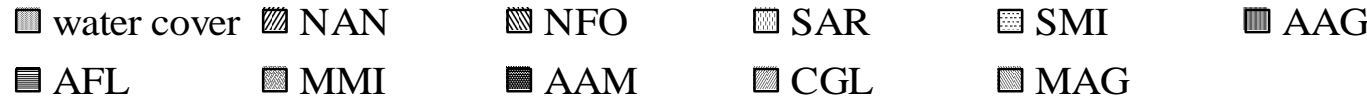

Plot 2

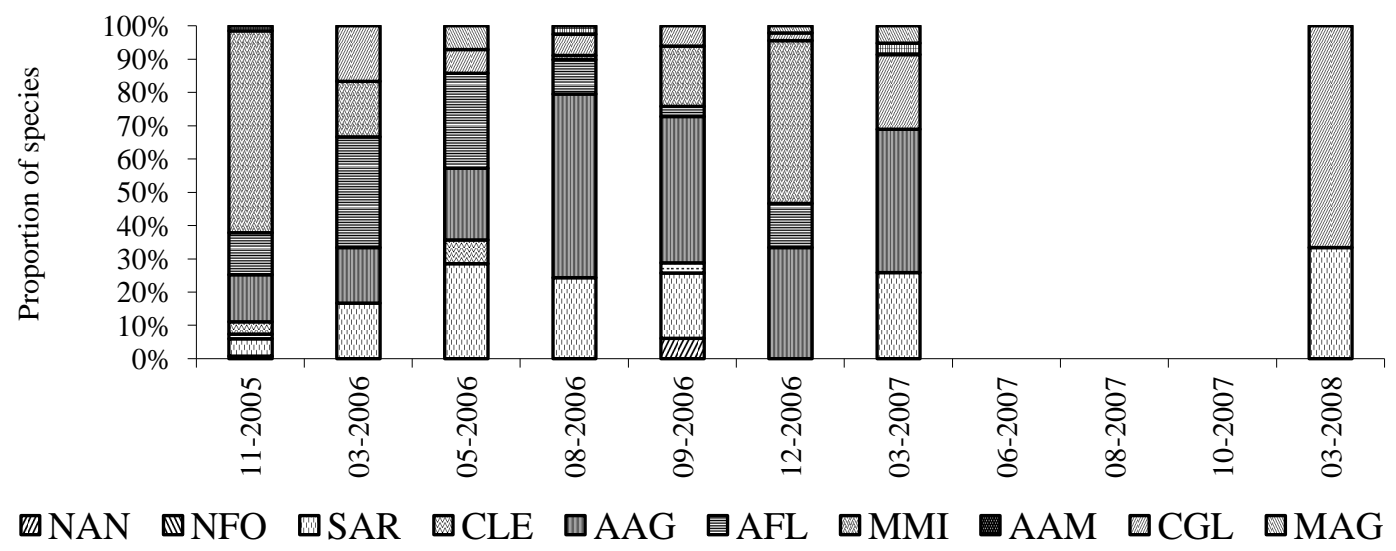

Plot 3

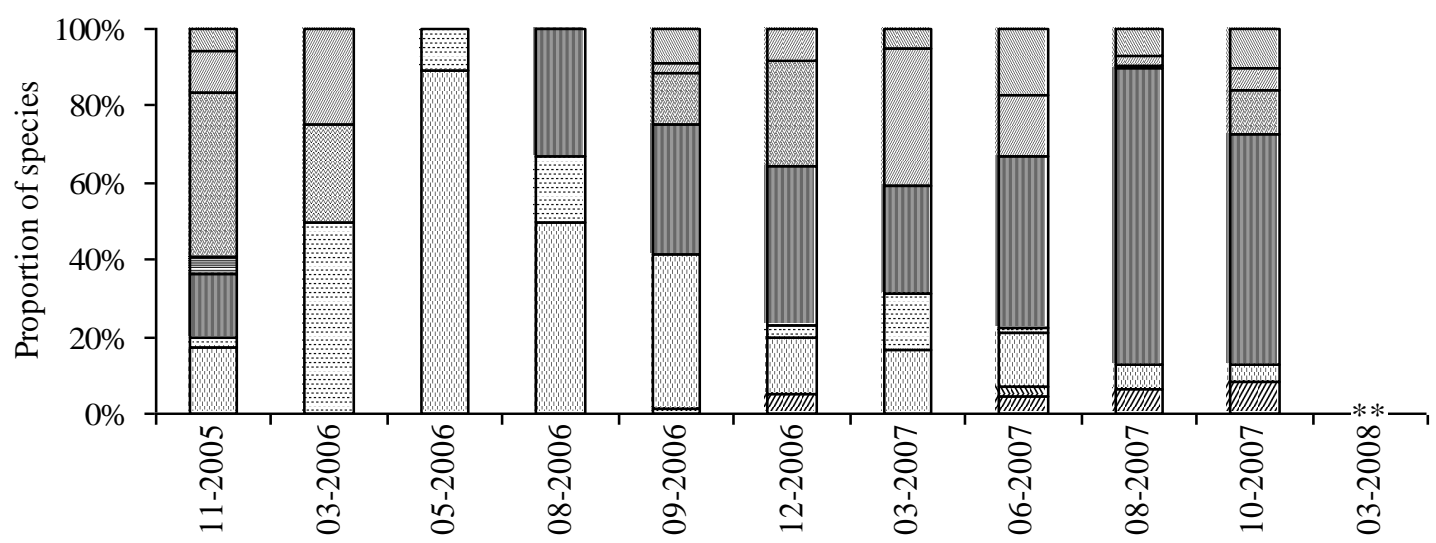

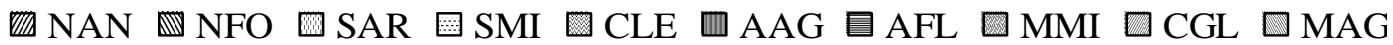

Figure 2. Percentage distibution of species of small mammal communities in the plots 1, 2, and 3 for various months in the years 2005-2008. NAN= Neomys anomalus, NFO= Neomys fodiens, 
$S A R=$ Sorex araneus, $S M I=$ Sorex minutus, $C L E=$ Crocidura leucodon, $A A G=$ Apodemus agrarius, $A F L=$ Apodemus flavicollis, MMI= Micromys minutus, MAG= Microtus agrestis, $M G L=$ Myodes glareolus. $*=$ no animals $* *=$ no data

Only four pygmy shrews were captured and moved within the plot 1 . Their preference was comparable at medium water level only. This species preferred the microhabitat of Carex acutiformis type, with dense plant cover (Fig. 6).

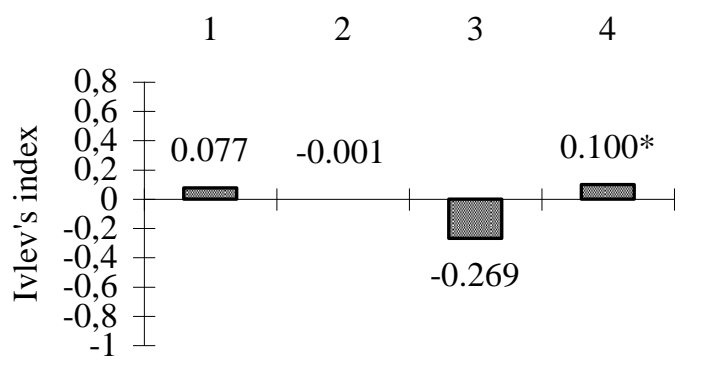

Low water level

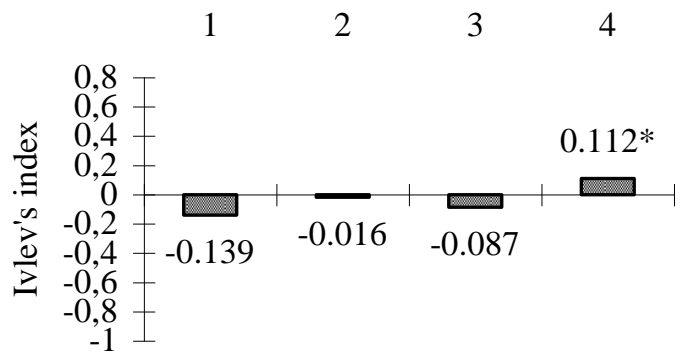

Medium water level 07/2008
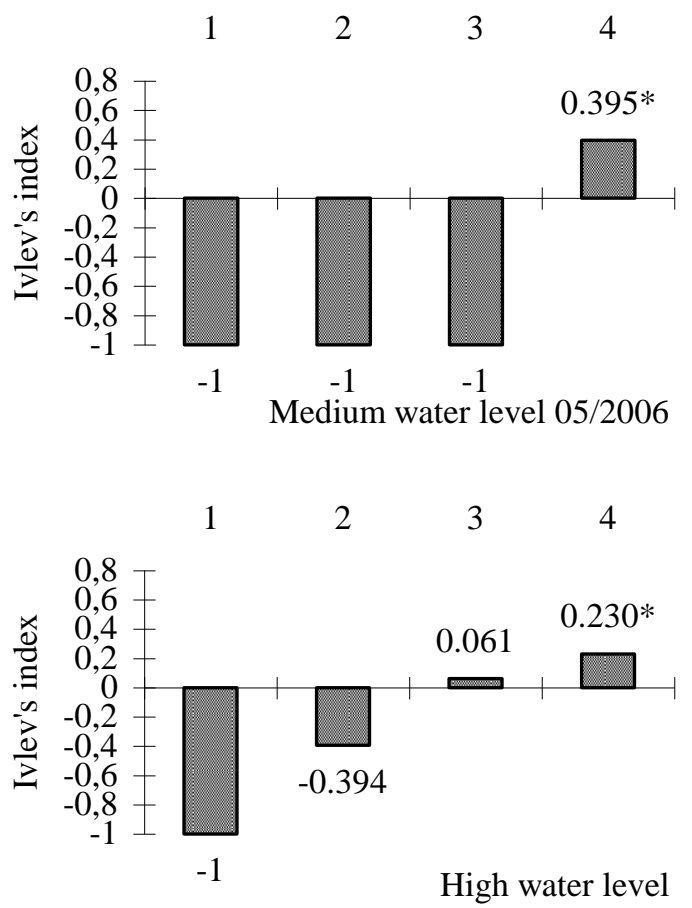

Figure 3. Microhabitat preferences of Neomys anomalus. Values with * are statistically significant ( $p<0.05)$. Numbers 1-4 mean the different microhabitat types: Bidens tripartitus type (1), Glyceria maxima type (2), Phragmites australis type (3), Carex acutiformis type (4).
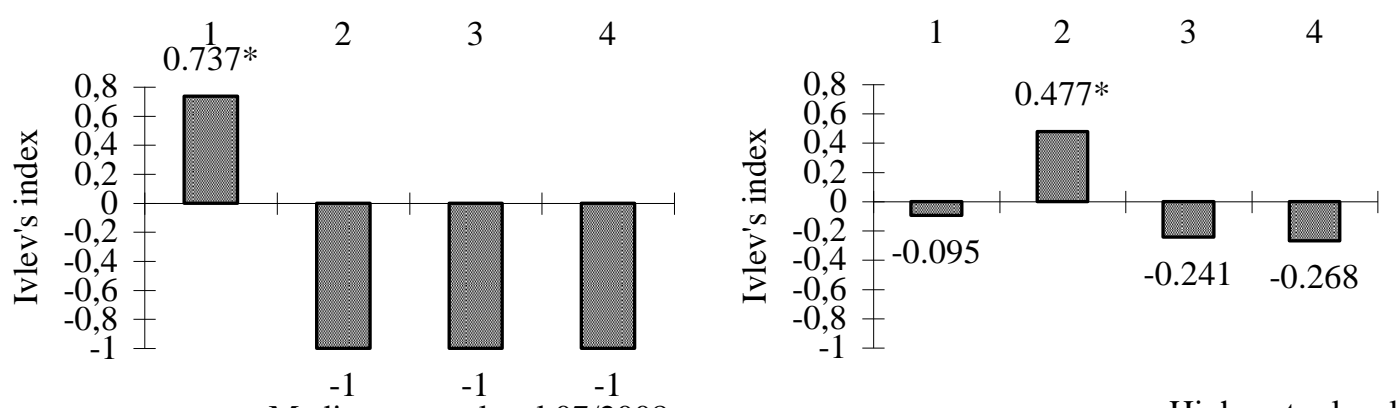

Medium water level 07/2008

High water level

Figure 4. Microhabitat preferences of Neomys fodiens. Values with * are statistically significant ( $p<0.05)$. Numbers 1-4 mean the different microhabitat types: Bidens tripartitus type (1), Glyceria maxima type (2), Phragmites australis type (3), Carex acutiformis type (4). 


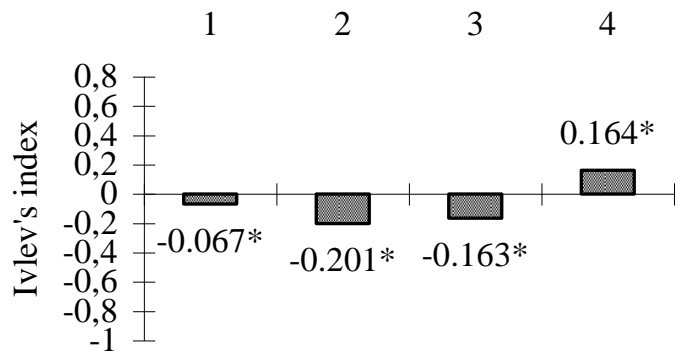

Low water level

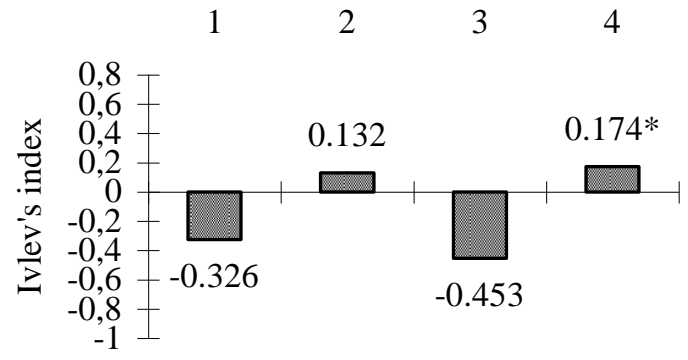

Medium water level 05/2006

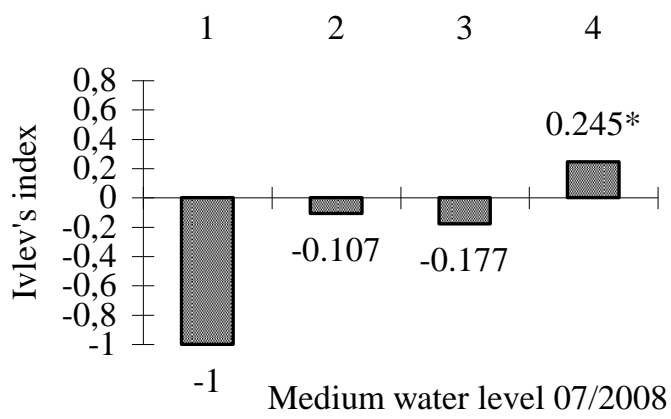

Figure 5. Microhabitat preferences, of Sorex araneus. Values with * are statistically significant ( $p<0.05)$. Numbers 1-4 mean the different microhabitat types: Bidens tripartitus type (1),

Glyceria maxima type (2), Phragmites australis type (3), Carex acutiformis type (4).
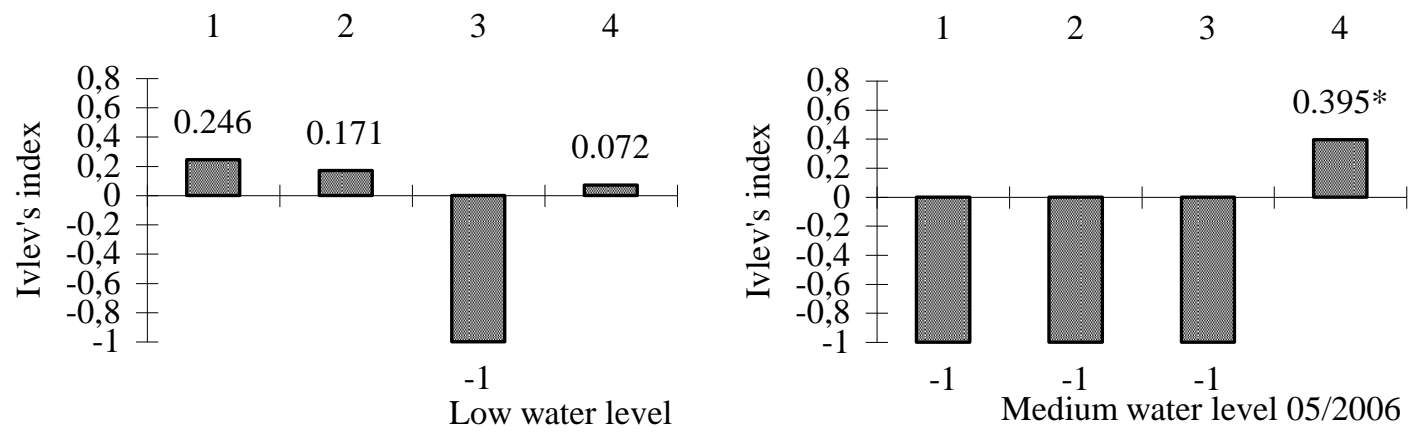

Figure 6. Microhabitat preferences of Sorex minutus. Values with * are statistically significant $(p<0.05)$. Numbers 1-4 mean the different microhabitat types: Bidens tripartitus type (1),

Glyceria maxima type (2), Phragmites australis type (3), Carex acutiformis type (4).

Bidens tripartitus vegetation covering a part of the plot 1 in 2005-2006 (during low and medium water levels) was replaced by rather open Carex vegetation in 2007-2008 (during high and medium water levels). This microhabitat was completely dry at low water level and then Neomys anomalus and Sorex araneus occupied it. No small mammal species occupied this microhabitat when it was completely under water. During this period Carex plants grew above the water only in summer months. At this time this microhabitat was inhabited by $N$. fodiens. The structure of vegetation in the 
Glyceria maxima microhabitat changed from season to season: it was very dense in summer, but in spring and autumn the plants tend to flatten. $N$. fodiens preferred this microhabitat in spring when it was still relatively open. In the Phragmites australis microhabitat, vegetation was dense and with the exception of $N$. anomalus during high water levels, all species avoided it. Even though the calculated results not always were significant, the Carex acutiformis microhabitat was preferred by every shrew species except $N$. fodiens.

The water level in particular habitat affected the species composition in a well defined manner. Two percent of the plot 1 was covered by water during low water level. At this time 3 shrew species (Neomys anomalus, Sorex araneus, and S. minutus) as well as 5 rodent species (Apodemus agrarius, A. flavicollis, Micromys minutus, Microtus agrestis, and Myodes glareolus) inhabited this plot. During spring flood (water cover = $100 \%$ ), all small mammals left the area. In June, however, $N$. anomalus returned and $N$. fodiens and Arvicola amphibius appeared. After the water level decreased to $66 \%$ of maximum in the middle of summer, the original species composition ,reappeared”: $N$. fodiens and Arvicola amphibius disappeared, and Sorex and rodent species immigrated back (Figs. 7 and 8). Neomys fodiens and Arvicola amphibius preferred high water levels while Sorex species, Apodemus agrarius and Myodes glareolus avoided them. Only a few Apodemus flavicollis specimen were trapped, not enough for statistical analysis.

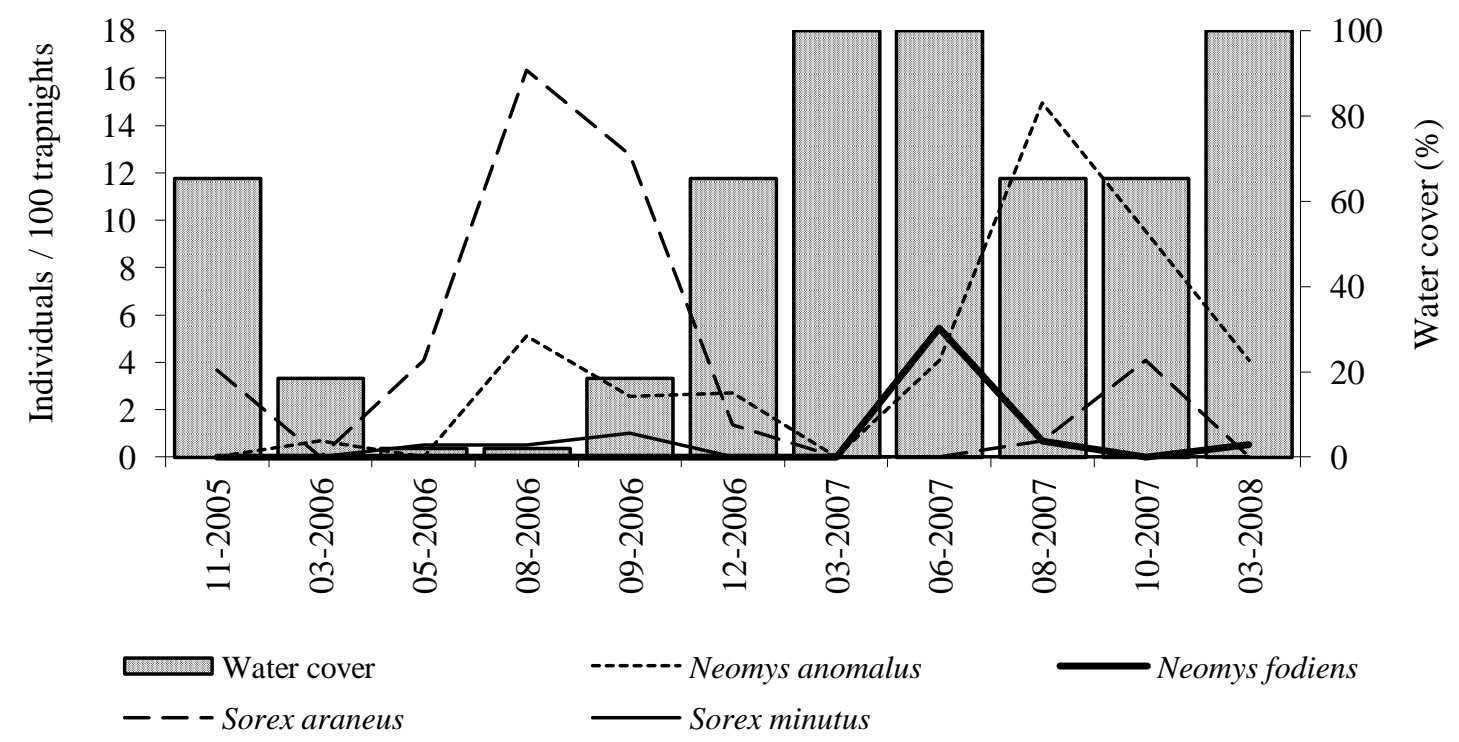

Figure 7. Number of shrew species trapped in the plot 1 during certain months of years 20052008.

The appearence of the small mammal species is highly dependent on season with the highest number recorded in summer. The traps were open from sundown until sunrise. During these hours there was little or no difference between the trapability of the animals. (Table 3). 


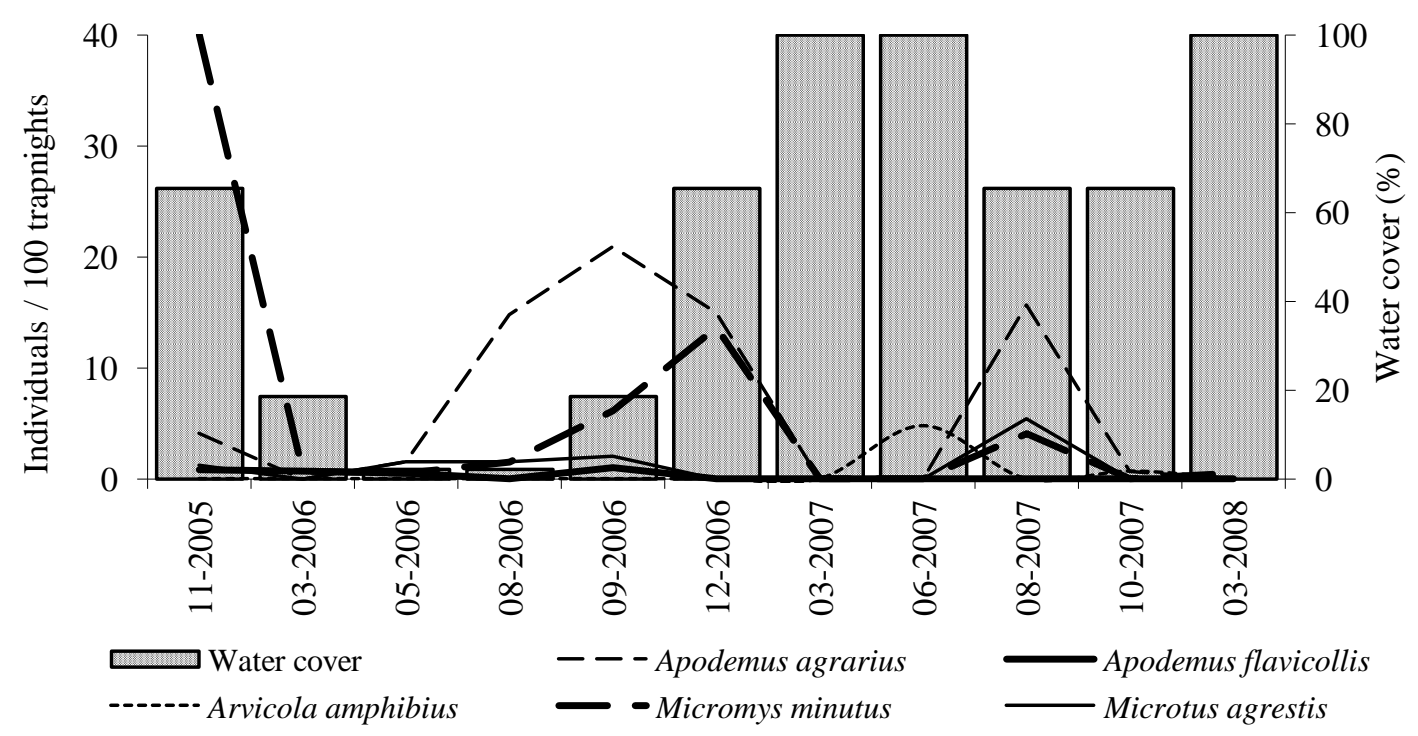

Figure 8. Number of rodent species trapped in the plot 1 during certain months of years 20052008.

Table 3. The results of variance component analysis (VCA). NAN= Neomys anomalus, $N F O=$ Neomys fodiens, $S A R=$ Sorex araneus, $S M I=$ Sorex minutus, $A A G=$ Apodemus agrarius, $A F L=$ Apodemus flavicollis, $M M I=$ Micromys minutus, $A A M=$ Arvicola amphibius, $M A G=$ Microtus agrestis, $M G L=$ Myodes glareolus. $n s=$ non significant $*=$ $p<0.05 \quad * *=p<0.01 \quad * * *=p<0.001$

\begin{tabular}{|c|c|c|c|c|c|c|c|c|c|c|}
\hline & NAN & NFO & SAR & SMI & AAG & AFL & MMI & AAM & MGL & MAG \\
\hline water cover & ns & & & & & ns & ns & & & ns \\
\hline season & $* * *$ & $* * *$ & ns & $\mathrm{ns}$ & $* * *$ & $\mathrm{~ns}$ & $* * *$ & $* * *$ & $\mathrm{~ns}$ & $\mathrm{~ns}$ \\
\hline year & $* * *$ & ns & $\mathrm{ns}$ & ns & * & ns & **** & ns & ns & ns \\
\hline month & $* * *$ & $* *$ & $* * *$ & ns & $* * *$ & ns & ns & * & $*$ & $* *$ \\
\hline day & ns & $\mathrm{ns}$ & ns & $\mathrm{ns}$ & ns & ns & ns & ns & ns & $\mathrm{ns}$ \\
\hline controll & ns & $\mathrm{ns}$ & ns & ns & ns & ns & ns & ns & ns & ns \\
\hline
\end{tabular}

preference $\mathrm{DD}$

avoidance

\section{Discussion}

Five of the seven Hungarian shrew species were caught in the study area. Among the Sorex species, common shrews and pygmy shrews coexist in many terrestrial habitats in Europe (Churchfield, 1990). The common shrew is the numerically dominant shrew species in central and eastern Europe (Hanski, 1992), as well as one of the most common shrew species in Hungary (Horváth, 2007). Pygmy shrews are subdominant usually; therefore its population size is much lower than that of the common shrew (Aulak, 1970). Members of the Crocidura genus prefer dry, warm habitats (Saarikko, 1989) and therefore, their appearence in our study plots was unexpected. A small number of $C$. leucodon was trapped only in the driest microhabitats. Subadult shrews explore new areas during dispersal, hence they can appear in habitats that are normally 
not preferred by the species (Dehnel, 1950). In these cases the subadult individuals are simply curious or are migrating to other habitats. (Churchfield, 1984, Churchfield et al., 2000). Shrew numbers can quickly decline for reasons not fully understood. In our studies the recapture rate during a 3-4 nights period was commonly high for rodents, but for shrews it was usually less than $10 \%$ despite the preferable bait for them. One reason for this is that shrews, in their first year of their life, tend to explore new areas and begin to take and defend their own territory only in autumn (Rychlik, 1998). Over 90\% of the shrews captured in this study represented first capture. This suggests that most captured individuals in the studied territory spent there short time only.

Only $20-30 \%$ of shrews survive to breed (Churchfield, 1980). This percentage agrees with our results in the Kis-Balaton region where $67-100 \%$ of the captured shrews were subadults. The overwintered shrews become mature and start to breed in spring (Rychlik, 1998). In accordance to this, adult shrews in all the studied plots were clearly most frequent in May-June. There was also a peak in the population of adult shrews in the plot 3 in 2007, when the plot 1 was colonized only by subadults in June because of a high water level. These facts demonstrate that subadults can colonize new territories, and that adults tend not to leave their terriories. In a newly colonized area adult shrews only appear in the second year.

More than half of the trapped shrews were females. The sex ratio at birth in natural populations varies and differences are significant only in June (in favour of males) and August (in favour of females) (Pucek, 1959). This suggest that females tend to remain in their established territories probably due to attend to their offspring. In contrast, males are more active, roam over larger areas searching for receptive females, and are exposed to greater predation rates than females (Cantoni, 1993; Rychlik, 1998).

The plot 1 contained various microhabitats. The structure and flora of these microhabitats differ from each other and change from season to season. Within a particular microhabitat the water level also changes due to changes in weather and/or human activity. Hence, the microhabitats are constantly changing and differ in quality as a function of season and water level. The Bidens tripartitus type is the most open microhabitat. The soil surface of this microhabitat is free of flora at the beginning of spring. By May it is covered by new plants. The small mammals, however, are not able to climb up to these plants; they can only move on the soil surface. The Phragmites australis usually mixed with Carex spp. This flora is dense but not tufted. The plants are able to reach above the water surface at high water level but the animals can hardly colonize them. The thick Carex vegetation represents the most compact microhabitat. The dry leaves form a tufted cover 1-1,5 $\mathrm{m}$ tall where the small mammals can move vertically. This area is usually full of small mammal tracks. It is the easiest microhabitat for shrews and small rodents to colonize during high water levels.

The larger species of shrews are often more abundant than the smaller species in the most productive habitats (Hanski, 1992). We found this to be true in the Kis-Balaton areas: the common shrew and the two water shrew species were the most abundant. The pygmy shrew lived there also but in small numbers.

All the trapped shrew species preferred different patches of vegetation (microhabitats). Neomys fodiens preferred open patches of Glyceria maxima with deep water. Neomys anomalus prefers an environment with dense plant cover and shallow water. Changes in water level do not appear to affect this species; we trapped it during all water levels. Its tolerance for changes in water levels apparently is wider than $N$. fodiens or Sorex araneus. Patches of Carex were preferred almost always by $N$. 
anomalus. These findings correspond to the low tolerance of this species to stress of open field and the clear preference to remain in hiding-places (Krushinska and Rychlik, 1993). The common shrew has the widest habitat tolerance among the Hungarian shrew species. In our study they disappeared during floods and returned after the water level decreased. Our findings indicate that common shrews prefer a microhabitat with patches of Carex but this species also uses the other patches more frequently than $N$. anomalus.

We observed that the impact of water level changes was strong. During the winter of 2007, the plot 1 was completely flooded. Hence, we found no small mammals during spring in that area, only in summer. We assume that small mammals are not able to find enough food to maintain themselves in a flooded territory in winter, and they are forced to leave. Because individuals are always exploring new areas, colonizable territories tend to be immediately inhabited.

Acknowledgments. The authors thank Zoltán Illyés to monitor the vegetation in the field. Bea Bolla, Tamás Görföl, Zsuzsa Kocsis, Melinda Molnár, Barnabás Ottlecz, Ágnes Regős, Anita Rózsás and Orsolya Zöld helped us in the field work. András Gubányi gave us instructions in the statistical analysis.

\section{REFERENCES}

[1] Andersen, D.C., Wilson, K.R., Miller, M.S., Falck, M. (2000): Movement patterns of riparian small mammals during predictable floodplain inundation. - Journal of Mammalogy 81: 1087-1099.

[2] Aulak, W. (1970): Small mammal communities of the Bialowieza National Park. - Acta Theriologica 15: 465-515.

[3] Blem, L.B., Blem, C.R. (1975): The effect of flooding on length of residency in the white-footed mouse, Peromyscus leucopus. - American Midland Naturalist 94: 232-236.

[4] Cantoni, D. (1993): Social and spatial organisation of free-ranging shrews, Sorex araneus and Neomys fodiens (Insectivora, Mammalia). - Animal Behaviour 45: 975-995.

[5] Churchfield, S. (1980): Population dynamics and the seasonal fluctuations in numbers of the common shrew in Britain. - Acta Theriologica 25: 415-424.

[6] Churchfield, S. (1984): An investigation of the population ecology of synoptic shrews inhabiting water-cress beds. - Journal of Zoology 204: 229-240.

[7] Churchfield, S. (1990): The natural history of shrews. - Helm, C. \& Black, C. Ltd., Bromley

[8] Churchfield, S., Barber, J., Quinn, C. (2000): A new survey method for water shrews (Neomys fodiens) using baited tubes. - Mammal Review 30: 249-254.

[9] Crowcroft, P. (1957): The life of the shrew. - Reinhardt, London

[10] Dehnel, A. (1950): Studies on the genus Neomys Kaup.. - Annales Universitatis Mariae Curie, Sklodowska Lublin, Polonia, 5: 52-61.

[11] Doyle, A.T. (1990): Use of riparian and upland habitats by small mammals. - Journal of Mammalogy 71: 14-23.

[12] Ellis, L.M., Molles, M.C.Jr., Crawford, C.S. (1997): Short-term effects of annual flooding on a population of Peromyscus leucopus in a Rio Grande riparian forest of central New Mexico. - American Midland Naturalist 138: 260-267.

[13] Geier, A., Best, L.B. (1980): Habitat selection by small mammals of riparian communities: evaluating effects of habitat alterations. - Journal of Wildlife Management 44: 16-24.

[14] Gliwicz, J., Jancewicz, E. (2001): Aging and cohort dynamics in Sorex shrews. - Acta Theriologica 46: 225-234. 
[15] Hanski, I. (1992): Insectivorous mammals. - In: Crawley, M.J. (ed.) Natural enemies: The population biology of predators, parasites and diseases, Blackwell Scientific Publications, Oxford

[16] Horváth, Gy. (2007): [Common shrew.] - In: Bihari, Z., Csorba, G. and Heltai, M. (eds.) [Atlas of Hungarian mammals], Kossuth Kiadó, Budapest (in Hungarian)

[17] Jacob, J. (2002): The response of small mammal populations to flooding. - Mammalian Biology 68: 102-111.

[18] Khylap, L.A. (1980): [Shrews]. - In: [Theoretical problems: Results of the marking experiments on mammals], Akademya Nauk (USSR), Editions „Sciences”, Moscow (in Russian)

[19] Krushinska, N.L., Rychlik, L. (1993): Intra- and interspecific antagonistic behaviour in two sympatric species of water shrews: Neomys fodiens and N. anomalus. - Journal of Ethology 11: 11-21.

[20] Lardet, J.-P. (1988): Spatial behaviour and activity patterns of the water shrew Neomys fodiens in the field. - Acta Theriologica 33: 293-303.

[21] Mohammadi, S. (2010): Microhabitat selection by small mammals. - Advances in Biological Research 4: 283-287.

[22] Pucek, Z. (1959): Some biological aspects of the sex-ratio in the common shrew (Sorex araneus araneus L.). - Acta Theriologica 3: 43-73.

[23] Ruffer, D.G. (1961): Effect of flooding on a population of mice. - Journal of Mammalogy 42: 494-502.

[24] Rychlik, L. (1998): Evolution of social systems in shrews. - In: Wójcik J.M., Wolsan, M. (eds) Evolution of shrews, Mammal Research Institute, Bialowieza

[25] Rychlik, L., Ruczyñski, I., Borowski, Z., Friedrich, T. (2004): Space use and competitive interactions in shrews (Insectivora: Soricidae) revealed by radio-telemetry. - In: Voigt, C., Hofer, H. (eds) Contributions to the 5th International Symposium on Physiology, Behaviour and Conservation of Wildlife, Berlin, Germany, 26-29 September 2004. Advances in Ethology 38, Suppl. to Ethology: 172.

[26] Saarikko, J. (1989): Foraging behaviour of shrews. - Annales Zoologici Fennici 26: 411423.

[27] Simonetti, J.A. (1989): Microhabitat use by small mammals in central Chile. - Oikos 56: 309-318.

[28] Tóthmérész, B. (1996): [NuCoSa: a program package for community studies in botany, zoology and ecology] - Scientia kiadó, Budapest (in Hungarian)

[29] Tóthmérész, B. (1997): [Diversity Orderings] - Scientia kiadó, Budapest (in Hungarian)

[30] Van Bemmel, A.C., Voesenek, L.A.C.J. (1984): The home range of Neomys fodiens (Pennant, 1771) in the Netherlands. - Lutra 27: 148-153.

[31] Wijnhoven, S., van der Velde, G., Leuven, R.S.E.W., Smits, A.J.M. (2006): Modelling recolonisation of heterogenous river floodplain by small mammals. - Hydrobiologia 565: 135-152. 